\title{
Development of a multi-media book for clinical super- vision training in an undergraduate nursing programme
}

\author{
Karen McCutcheon \\ Queen's University Belfast, United Kingdom
}

Correspondence: Karen McCutcheon. Address: School of Nursing and Midwifery, Queen's University Belfast, 97 Lisburn Road, Belfast, Northern Ireland, BT97BL, USA. Telephone: 02-890-972-387. Email: k.mccolgan@qub.ac.uk.

Received: June 20, 2012

Accepted: November 8, 2012 Online Published: December 10, 2012

DOI : $10.5430 /$ jnep.v3n5p31

URL: http://dx.doi.org/10.5430/jnep.v3n5p31

\begin{abstract}
There is an increased interest in higher education in the use of e-learning resources for students. This can be attributed to many factors including, the availability of advanced technology systems, a growing student population that is technology focused, financial implications and the recruitment of international students. However, the introduction of technology and e-learning into teaching has given rise to issues regarding quality and quantity of educational practice. The challenge now is for educationalists is to deliver an optimal learning experience that is effective and appropriate for students' learning needs.
\end{abstract}

\section{Key words}

Clinical supervision, E-learning, Blended learning, Multi-media book

\section{I ntroduction}

Clinical supervision can be broadly defined as a process of reflective facilitation that leads to a transformative, educative professional growth. It can involve one to one supervision or group supervision from either peers or a more experienced nurse. Its primary goal ${ }^{[1]}$ is the improvement of patient care and safety through the development of competent practitioners. Clinical supervision is a mandatory process for United Kingdom (UK) midwives following the implementation of the Nurses Midwives and Health Visitors act $1997^{[2]}$. The Nursing and Midwifery Council (NMC) in the UK, supports the establishment of supervision as an important part of clinical governance and is in the interests of improving standards of patient care ${ }^{[3]}$. However, although clinical supervision has been widely accepted as a means to support clinical governance and improve standards of care, its implementation has been haphazard within the nursing profe$\operatorname{ssion}{ }^{[4,5]}$.

One of the recommended training courses for registered nurses in Northern Ireland is clinical supervision training. In 2007 the Chief Nursing Officer (CNO) for Northern Ireland published two standard statements for clinical supervision ${ }^{[6]}$.

\section{Standard statement 1}

Supervision will contribute to the delivery of safe and effective care when practitioners have access to appropriate systems that facilitate the development of knowledge and competence through a culture of learning by reflection. 


\section{Standard statement 2}

An organisational framework supporting effective leadership and performance management will ensure that supervision will become an effective tool to improve the safety and quality of care.

These standards followed on from a series of regional and national healthcare related critical incident reviews within the UK such as the Bristol Inquiry ${ }^{[7]}$ and Murtagh Inquiry ${ }^{[8]}$. The Department of Health (DOH) indicated that effective supervision can help organisations meet their clinical and social care governance standards ${ }^{[6,9]}$. The publication of these standards has recommended a uniform approach to the provision of clinical supervision within Northern Ireland; however, its implementation has yet to be achieved.

Clinical supervision is not currently taught in the undergraduate adult nursing curriculum and is commonly misinterpreted as being similar to mentorship ${ }^{[5,10]}$. However, although clinical supervision has similarities to the role of mentorship, there are distinct differences. Mentorship in undergraduate nursing is assessment focused with a mentor observing the student and providing feedback on performance. Clinical supervision involves a supervisor who has not observed a person's work and facilitates learning by encouraging the supervisee to learn through reflection of their experiences. Therefore it is reasonable to suggest that this misinterpretation of what clinical supervision is, has contributed to its lack of inclusion in the undergraduate Adult nursing curriculum.

There are three studies available that consider the use of clinical supervision in undergraduate nursing curriculum. Staun and colleagues ${ }^{[11]}$ explored the perceptions of nursing students in Sweden on the use of reflective clinical supervision and problem based learning. The study concluded that by using reflective supervision in practice, students may be better prepared for the role of a registered nurse. This is a small scale evaluative study that did not use a comparative group of students and therefore its conclusions are limited in terms of generalisability. However, it seems reasonable to assume that the introduction of reflective clinical supervision skills in undergraduate nursing could make the transition from student to qualified nurse a more widely accepted and anticipated aspect of the nurses' continuing educational pathway. This has significance as barriers to effective clinical supervision can be related to a lack of supervisee understanding of the process viewing it more as a managerial supervision session than a learning and developmental session ${ }^{[5,12]}$.

This barrier, related to supervisee misinterpretation resulting in viewing clinical supervision as a managerial tool, is explored further by Carver and colleagues ${ }^{[13]}$. They examined the expectations of mental health nursing students and group clinical supervision. It is notable that the students in this study, although recognising the supportive nature of supervision, remained anxious and fearful of the general aspects of supervision. This research study's conclusion supports the notion of barriers to effective supervision identified by Gilmore ${ }^{[12]}$ and Bush ${ }^{[5]}$. Therefore, it would seem reasonable to suggest that by introducing clinical supervision into the undergraduate curriculum some of these barriers could be broken down. However, the conclusions gained from this study has many limitations, not least in terms of generalisability due, in part, to the qualitative methods used.

To try and bridge these barriers, Haggman-Laitila and colleagues ${ }^{[4]}$ provided educators and practitioners with a clinical supervision model for nursing students. The researchers used a collaborative approach involving all those concerned in the process of clinical supervision. By using a collaborative, all inclusive approach the barrier of supervisee misinterpretation is avoided. However, although the researchers acknowledge the link to lifelong learning and self evaluation, remarkably they do not include reflection as a process aspect. The final conclusion of this study is that future research should be directed at developing supervision learning practices.

These three studies ${ }^{[11,13,14]}$ have suggested that by introducing clinical supervision skills to undergraduate nursing students this may better prepare them for the registered nurses' role and create a seamless transition from that of mentee to supervisee. 
There is an increased interest in higher education in the use of e-learning resources for students. The introduction of this supervisee training has taken cognisance of this and a multi-media book has been developed to deliver this training. This increased interest in technology can be attributed to many factors including, the availability of advanced technology systems, a growing student population that is technology focused, financial implications and the recruitment of international students. However, the introduction of technology and e-learning into teaching has given rise to issues regarding quality and quantity of educational practice ${ }^{[15,16]}$. The challenge now is for educationalists is to deliver an optimal learning experience that is effective and appropriate for students' learning needs.

Technology based learning increases flexibility in delivery and removes any geographical or time constraints that traditional face to face learning poses ${ }^{[17]}$. Several studies have favourably reviewed the introduction of online or e-learning teaching pedagogies ${ }^{[18-20]}$. However, there are a number of recognised challenges involved in the delivery of this form of teaching. The student uptake with this form of learning is not always guaranteed and the time students spend learning also requires monitoring ${ }^{[21]}$. There are also a limited number of studies ${ }^{[22,23]}$ available that fully explore the students' satisfaction with an e-learning pedagogy, with the majority of studies focusing on the outcomes of learning and assessment.

Within Northern Ireland and the rest of the UK there is a sporadic use of e-learning resources available within undergraduate and postgraduate nursing courses. This is due to numerous factors such as lecturer experience, lack of training and support, availability of e-learning resources and an overriding fear of the loss of control in the classroom setting. This paper describes the development of a multi-media book for clinical supervision training in an undergraduate adult nursing programme. A description of the resources framework and the theory supporting its design is explored and discussed.

\section{Theoretical framework}

From a cognitive perspective a skill is an activity that requires training and experience to perform well ${ }^{[24]}$. This definition is further explored with acknowledgement that a skill is also developed through repetition of a task ${ }^{[25]}$. Anderson's cognitive theory of intelligence and development ${ }^{[26]}$ supports the notion of declarative and procedural knowledge, whereby procedural knowledge follows on from declarative knowledge. Anderson's theory consists of three phases and the e-learning resource discussed here is designed using these principles. By applying these three phases the student is supported and guided through the early processes of skills acquisition. Anderson's cognitive theory of intelligence and development consists of three phases and supports the notion of declarative and procedural knowledge, whereby declarative knowledge is important prior to procedural knowledge.

Declarative stage: the declarative stage is the teaching of theoretical principles providing the learner with the knowledge of who, what, how and why. During this stage the students will be given information on the conceptual principles of clinical supervision. This provides the student with the knowledge required to understand the principles of clinical supervision.

Knowledge compilation stage: this stage encourages the learner to translate the declarative knowledge into procedural knowledge. The students undertaking this training receive information that encourages them to develop and create the rules that govern supervision.

Tuning stage: the tuning stage is when the learner develops and generalises their practice or 'fine tunes' the skill. During this stage the students are encouraged to 'fine tune' their skill and apply their learning to a variety of different clinical situations. 


\section{Development of the clinical supervision training}

Although clinical supervision has been identified as important for professional governance in healthcare since the 1990's it remains an area that is under investigated and requires further development. The initial supervisee training is recognised by key stakeholders, managers and educationalists alike, as an important requirement for the success of clinical supervision in practice ${ }^{[6,17,27]}$. However, the introduction of clinical supervisee training takes place following qualification once the newly qualified nurse is employed in clinical practice. Often the variety and diversity of nursing jobs can result in a hit and miss delivery of supervisee training. By introducing supervisee training uniformly at undergraduate level a more consistent and seamless transition may occur in the introduction of post registration clinical supervision.

\section{Description of the multi-media book}

Higher education institutions are being encouraged to increase and develop strategies for e-learning ${ }^{[28]}$. There are a variety of reasons identified for this such as the need to remain current with the national and international markets and also to engage the student to develop active learning skills through the use of technology, preparing them for employment in today's technology based society ${ }^{[29]}$.

With consideration to Anderson's theory ${ }^{[26]}$ a multi-media book has been designed to mimic the traditional didactic classroom teaching, already established for supervisee training with registered nurses. The decision to use a multi-media book as a learning resource for supervisee training was selected for a number of reasons. The primary reason was due to the availability of the software programme within the faculty. Other reasons included the ease of use for the instructor as its content input has similarities with Microsoft office, a commonly used media system thereby making the development less daunting for the lecturer. The ease of use for the student was also a main consideration, as UK studies have shown that nursing students tend to have a lower level of computer literacy unlike their contemporaries in South East Asia ${ }^{[30]}$.

It is intended that this multi-media book will be accessible to undergraduate third year management students via the Queen's University Belfast's online module management system. This multi-media book is similar in design to that of an e-book, but is more advanced including video clips, audio podcasts and interactive assessment tools. It is an e-learning resource that is downloadable to a laptop or computer. Although other more advanced technologies exist such as mobile learning with the use of iPod Touch in Singapore, this technology was chosen due to the low cost and resource availability for this mode of delivery.

This multi-media books visual appearance and display, mimics that of a paper book. Wilson ${ }^{[31]}$ suggested that a successful electronic book will have considered ergonomics, style and layout. However, unlike a paper book this multi-media book has kept the written text to a minimum, and instead encourages the student to construct their knowledge through directed investigative means. This has been achieved by including useful hyperlinks to internet sites and interactive tests.

It is important to design the multi-media book with student interactive learning activities to maintain the students' interest and test knowledge and understanding. Students are able to navigate back and forward through the electronic book as often as they need to, to complete the training. Unlike a paper text book the multi-media book deviates away from the traditional linear flow of text. However, it is important to make the electronic book resemble a paper book with logical structure and tables of content as students will approach this technology with paper book expectations ${ }^{[31,32]}$. To ensure that students are guided correctly in the use of this multi-media book the front cover includes a 'How to use this multi-media book' set of instructions.

This multi-media book begins by introducing the student to the local and national guidelines of clinical supervision. The student is then directed via the use of hyperlinks to a number of relevant critical incident inquiries. By providing the necessary background and theoretical framework the student can begin to contextualise and understand the importance of clinical supervision in practice. Following on from the background and context of supervision is the actual process of 
supervision. This section includes a number of interactive tests and also two short video clips, one of which is an animated supervision session. By blending audio, video and textual information a more motivating and stimulating learning experience is possible ${ }^{[33,34]}$. Next the student is asked to consider a set of reflective questions concerning a personal practice issue. These questions have been adapted from Northern Ireland's Practice Education Council (NIPEC) Development Framework which provides online resources that support the supervision of registered nurses ${ }^{[35]}$.

The responses given to these questions are then used by the nurse to form the basis of their first clinical supervision session in practice.

The final pages of the multi-media book includes a multiple choice question (MCQ) self assessment that tests process and products of learning. This type of formative assessment will provide the student with rapid feedback on their understanding and knowledge of the e-book content. Although there are many recognised limitations to this type of formative assessment, some studies have highlighted the usefulness of providing students with the opportunity to self correct and self assess using MCQ's ${ }^{[36,37]}$. The multi-media book can be described as an open book, that can be accessed as often as the student wants. The software facility also enables the student to input their responses as often as they require. By having an open book students are able to reflect on their MCQ scores and rescan this e-learning resource to find the correct information.

One of the central aims of this teaching resource is to motivate the student to identify explicit examples from their clinical experience to encourage change and promote personal development. However, one of the main issues regarding the introduction of supervisee training in undergraduate nursing centres on the student's lack of work experience ${ }^{[11,13]}$. By introducing supervisee training to students in their final year this issue of workplace inexperience should be less problematic, as students will have developed a two year clinical portfolio.

\section{Discussion}

There are a variety of e-learning resources available to educators and the rapid development of technology is continually adding to this inventory. However, the delivery of an e-learning modality is still relatively underused in higher education ${ }^{[38]}$. The reason for this is contributable in part to teacher inexperience and the comfort and safety of teaching by tried and tested traditional face to face teaching ${ }^{[38,39]}$. By developing partnerships with computer technicians and the purchase of user friendly software programmes, barriers to the implementation of e-learning can be removed. Lison and colleagues ${ }^{[39]}$ commented that strong partnerships with computer scientists are necessary to develop successful e-learning units. However, they also stated that these partnerships are not without problems, with disagreements about design and the lack of available time to work together developing e-learning resources ${ }^{[39]}$.

The observations made from the development of this e-learning resource raise a number of key issues that are based on the consumers need and modern student centred clinical education. The development of this multi-media book included a joint collaboration and exploration of the issue involving educators, service users and a computer technician. Common to the development of any educational programme a collaborative approach is essential to ensure the success of the delivery and student uptake of the programme ${ }^{[40]}$. The end result is that the prototype for this multi-media book is now available within the faculty and could be adapted to suit other nursing professional issues and clinical skill development.

One aspect that is challenging within an e-learning environment is the educator's loss of control and ability to adapt the classroom teaching to meet evolving students' needs ${ }^{[17]}$. The traditional face to face approach to training enables the trainer to make assessments of students' knowledge and judge the delivery and direction of their teaching to suit the

students' requirements ${ }^{[40]}$. With the change to a virtual learning experience, educators need to adapt and develop their teaching skills to provide continued support to students undertaking this type of learning. One study concluded in their 
review of student e-learning experiences, that teachers need to give explicit instructions to students as to the purpose and expectations of any online activity they are asked to engage in ${ }^{[41]}$.

\section{Conclusion}

Clinical supervision has been highlighted by the $\mathrm{DOH}$ and other international health agencies as significant to creating and providing safer clinical practice ${ }^{[6,11,14]}$. The provision of quality staff training is important to ensure engagement and understanding of the process occurs. By providing training in clinical supervision to undergraduate final year nurses via an e-learning resource, introduction to the supervision process post registration should become a seamless transition ${ }^{[11,13,14]}$. A study that explores the students' use of e-learning as a means to acquire skills and a comparison of traditional learning versus online learning is necessary to establish the value of technology based learning in the healthcare setting.

The development of this e-learning resource is a useable interactive training programme that is consistent with the changing needs of local and national policy. The development of technology based learning and teaching approaches are becoming more widely used. Thus it seems prudent that these are appropriately evaluated and explored for quality assurance purposes.

With higher education facilities encouraging the development of technology based learning, appropriate support and training is essential for the educators delivering the teaching. The provision of training and support is also essential for those in senior management to ensure that they can provide appropriate direction in the use of technology and begin championing this pedagogic style of teaching ${ }^{[28]}$. By working in collaboration with computer technicians, software programmers and the wider university community, educators can begin to develop skills and confidence in teaching using e-learning resources.

\section{Conflict of interest statement}

No conflicts of interest declared by the author.

\section{Acknowledgement}

Acknowledgement is given to Paul Morris clinical education technician for his support in the development of this multi-media book and doctoral supervisors Dr. Maria Lohan and Dr. Marian Traynor.

\section{References}

[1] Department of Health. Making a Difference: Clinical supervision in Primary Care. HMSO, London. 2000.

[2] United Kingdom Central Council. Nurses, Midwives and Health Visitors Act 1997. HMSO, London. 1997.

[3] Nursing and Midwifery Council. The Code - Standards of Conduct, Performance and Ethics for Nurses and Midwives. NMC, London. 2008.

[4] Teasedale K., Brocklehurst N., Thorn N. Clinical supervision and support for nurses: an evaluation study. Journal of Advanced Nursing. 2001; 33(2): 216-224. http://dx.doi.org/10.1046/j.1365-2648.2001.01656.x

[5] Bush T. Overcoming the barriers to effective clinical supervision. Nursing Times. 2005; 101(2): 38-42. PMid:15688921

[6] Department of Health and Social Services and Public Safety, Standards for Supervision for Nursing. DHSSPS, Belfast.2007.

[7] Bristol Royal Infirmary Inquiry. The Bristol story. BRII, Crown Copyright. 2001.

[8] Regional Quality Improvement Authority. Review of the Lessons Arising from the Death of the Late Janine Murtagh. RQIA, Belfast. 2005.

[9] Department of Health. Building a Safer NHS for Patients.Implementing an Organisation with a Memory. DOH, London. 2001.

[10] Quinn F., \& Hughes S. Quinn's Principles and Practice of Nurse Education 5th edition. Nelson Thornes, London. 2007.

[11] Staun M., Bergstrom B., Wadensten B. Evaluation of a PBL strategy in clinical supervision of nursing students:patient-centred training in student-dedicated treatment rooms. Nurse Education Today. 2010; 30(1): 631-637. PMid:20061069

http://dx.doi.org/10.1016/j.nedt.2009.12.013 
[12] Gilmore A. Clinical supervision in nursing and health visiting: a review of the UK literature. In: Fundamental Themes in Clinical Supervision (eds Cutcliffe J, Butterworth T and Proctor B), pp125-140. Routledge, London. 2001.

[13] Carver N., Ashmore R., Clibbens N. Group clinical supervision in pre-registration nurse training: the views of mental health nursing students. Nurse Education Today. 2007; 27(1): 768-776. PMid:17141379 http://dx.doi.org/10.1016/j.nedt.2006.10.010

[14] Haggman-laitila A., Elina E., Riitta M., Kirisi S., Leena R. Nursing students in clinical practice-developing a model for clinical supervision. Nurse Education in Practice. 2007; 7 (11): 381-391. PMid:17936544 http://dx.doi.org/10.1016/j.nepr.2006.11.011

[15] Garrison D., Kanuka H. Blended learning: Uncovering its transformative potential in higher education. Internet and higher Education. 2004; 7(12): 95-105. http://dx.doi.org/10.1016/j.iheduc.2004.02.001

[16] Swenson P. \& Redmond P. Online, hybrid, and blended coursework and the practice of technology-integrated teaching and learning within teacher education. Teacher Education. 2009; 18(2): 3-10.

[17] McColgan K., Rice C. An online training resource for clinical supervision. Nursing Standard. 2012; 26(24): 35-40. PMid:22443011

[18] Spickard A., Alrajeh N., Corday D., Gigante J. Learning about screening using an online or live lecture:does it matter? Journal of General Internal Medicine. 2002; 17(7): 540-545. PMid:12133144 http://dx.doi.org/10.1046/j.1525-1497.2002.10731.x

[19] Kerfoot B., Conlin P., Travison T., Mcmahon G. Web-based education in systems-based practice:a randomized trial. Archives of Internal Medicine. 2007; 167(4): 361-366. PMid:17325297 http://dx.doi.org/10.1001/archinte.167.4.361

[20] Chenkin J., Lee S., Huynh T., Banderia G. Procedures can be learned on the web: a randomised study of ultrasound-guided vascular access training. Academic Emergency Medicine. 2008; 15(10): 949-954. PMid:18778380 http://dx.doi.org/10.1111/j.1553-2712.2008.00231.x

[21] Hansen M. Are nursing students' clinical skills competency and self confidence levels improved via video ipods? A randomised controlled pilot study. Journal of Nursing Education and Practice. 2011; 1(1): 32-41. http://dx.doi.org/10.5430/jnep.v1n1p32

[22] Hong K., Lia K., Holton D. Students satisfaction and perceived learning from a web based course. Educational Technology and Society. 2003; 6(1): 223-234.

[23] Arbaugh J., Hornik S. Do Chickering and Gamson’s Seven Principles Also Apply to Online MBAs? The Journal of Educators Online. 2006; 3(2): 2-18.

[24] Card S., Newell A., Moran N. Computer text-editing: An information-processing analysis of a routine cognitive skill. Cognitive Psychology. 2004; 20(1): 32-74.

[25] Farrimond H., Dornan T., Cockcroft A., Rhodes L. Development and evaluation of an e-learning package for teaching skin examination. Action research. British Journal of Dermatology. 2006; 155(8): 592-599. PMid:16911287 http://dx.doi.org/10.1111/j.1365-2133.2006.07360.x

[26] Anderson J. Intelligence and Development a cognitive theory. Willey-Blackwell, UK.1992.

[27] Milne D., James I. The observed impact of training on competence in clinical supervision. British Journal of Clinical Psychology. 2002; 41: 55- 72. http://dx.doi.org/10.1348/014466502163796

[28] Higher Education Funding Council for England. Enhancing Learning and Teaching through the use of Technology. HEFCE, Bristol. 2009.

[29] Queen’s University Belfast. E-Learning and Distance Learning Policy 2009-2012. Available from: https://home.qol.qub.ac.uk/default.aspx (accessed 24.02.11)

[30] Wharrad J., Cook E. \& Poussa C. Putting post-registration nursing students on-line: important lessons learned. Nurse Education Today. 2005; 25 (4): 263-271. PMid:15896411 http://dx.doi.org/10.1016/j.nedt.2004.12.003

[31] Wilson R. E-book readers in higher education. Journal of Educational Technology Society. 2003; 6(4): 8-17.

[32] Landoni M., Wilson R., Gibb F. The role of visual rhetoric in the design and production of electronic books: the visual book. The Electronic Library. 2000; 18(3): 190-201. http://dx.doi.org/10.1108/02640470010337490

[33] MacDonald J. Blended Learning and Online Tutoring: Planning learner Support and Activity Design. Gower Publishing limited, Hampshire. 2008.

[34] Carvalho A., Lustigova Z., Lustig F. Integrating new technologies into blended learning environments. In Stacey E. \& Gerbic P. (eds) Effective Blended Learning Practices. IGI Global, New York. 2009.

[35] NIPEC. Supervision Record. 2008. Available from: http://www.nipecdf.org/portfolio/supervisionIntro.asp?show=7\#7 (accessed 05.04.12)

[36] Honey M., Marshall D. The impact of on-line multi-choice questions on undergraduate student nurses’ learning. In: Crisp G., Thiele D., Scholten I., Barker S., Baron J. (Eds.), Interact, Integrate, Impact. ASCILITE, Australia, pp.110-142. 2003.

[37] Nichol D. E-assessment by design: using multiple-choice tests to good effect. Journal of Further and higher Education. 2007; 31(1): 53-64. 
[38] Wiesenberg F., \& Stacey E. Blended learning and teaching philosophies:implications for practice.In: Stacey E., \& Gerbic P. (Eds.), Effective Blended Learning Practices. IGI Global, New York, pp. 342-404. 2009. http://dx.doi.org/10.1080/03098770601167922

[39] Lison T., Gunther S., Ogurol Y., Pretschner D., Wiscnesky M. VISION 2003: Virtual learning units for medical training and education. International Journal of Medical Informatics. 2004; 73(11): 165-172. http://dx.doi.org/10.4018/978-1-60566-296-1.ch011

[40] Biggs J., Tang C. Teaching for quality learning at university (3rd Ed.) Open University Press, Berkshire. 2007. PMid:15063376 http://dx.doi.org/10.1016/j.ijmedinf.2003.11.025

[41] Sharpe R., \& Benfield G.The student experience of e-learning in higher education. Brookes e-Journal of Learning and Teaching 2005; 1(3): 1-10. 